\title{
The effect of cold working and solution heat treatment on microstructure and mechanical behavior of Ti35Nb2.5Sn alloy
}

\author{
Silvando Vieira dos Santos ${ }^{1}$ \\ Gustavo Dória Lima 2* (1) \\ Brenno Lima Nascimento ${ }^{2}$ \\ Lucas Silva Fontes ${ }^{2}$ \\ Sandro Griza ${ }^{2}$
}

\begin{abstract}
Recently, $\beta$ Ti alloys have been extensively studied, due to their advantageous properties. $\beta$ titanium alloys can exhibit lower elastic modulus and may be produced by elements that do not exhibit cytotoxicity, such as niobium, molybdenum and zirconium. This study aims to evaluate the correlation between cold working and solution heat treatment regarding to the microstructure and hardness of the Ti35 Nb2.5Sn alloy. The alloy was arc melted in inert atmosphere and the ingots were hot rolled with $40 \%$ reduction. Axial compression samples were then cold worked with $40 \%, 70 \%, 80 \%$ and $90 \%$. After the cold working, the samples were then divided into two groups. In half of them, solution and quenching treatment was performed. Microstructural characterization was achieved by optical microscopy and X-ray diffraction. Vickers microhardness tests were also evaluated. The microstructural characterization confirmed the presence of $\beta$, $\alpha$ " and $\omega$ phases. Cold working above $70 \%$ reduction provides the increase of microhardness, which can be attributed to the grain refinement and others microstructural features, as the amount of strain induced $\alpha$ ", the amount of the $\omega$ phase - when it is present, and also by the dislocation density.
\end{abstract}

Keywords: Ti35Nb2.5Sn; Beta titanium alloys; Heat treatment; Cold working.

\section{Introduction}

The most attractive properties of titanium $\beta$ alloys for a variety of engineering fields comprises high strength, low density and excellent corrosion resistance. These properties are of interest to several engineering fields such as biomedical, aeronautic, automotive, defense, energy, among others $[1,2]$. The search for alloys that undergo increase in mechanical properties and corrosion resistance, but decrease in elastic modulus, is a challenge for the biomedical field. Several TiNb alloys are very ductile due to their body cubic centered $\beta$ matrix [3]. Therefore, they are subjected to mechanical property enhancement through cold working and heat treatments. The thermomechanical processes cause increase of strength, hardness, fatigue and corrosion resistance. They may also decrease the elastic modulus, toughness and ductility [4].

The insertion of niobium $(\mathrm{Nb})$ and tin $(\mathrm{Sn})$ in Ti- $\beta$ alloys has shown to be very promising, mainly regarding to the mechanical strength and density ratio. The interest by the technological innovation in TiNbSn alloys results from the potential advantages of these alloys in relation to the strength/ specific weight ratio, high fatigue and corrosion strength, shape memory, biocompatibility, toughness, ductility and elastic modulus $[1,5,6]$. Cold work is a very common way to enhancing the strength of most metal alloys. Some studies have investigated the cold working and aging effects on the mechanical properties of TiNbSn alloys [6-11].

The hot rolled Ti35 $\mathrm{Nb} 2.5 \mathrm{Sn}$ alloy presented promising mechanical strength to elastic modulus ratio, as well as promising ductility [5], as a result of the $\mathrm{Nb}$ addition, which increases the $\beta$ phase stability and decreases $\alpha$ " phase transformation. According to Griza et al. [5], TiNb alloys containing up to $2.5 \%$ Sn does not suppress the $\alpha$ " phase, which is achieved only above $5 \% \mathrm{Sn}$ content [5]. The $\mathrm{Nb}$ content increase up to $42 \%$ can reduces the elastic modulus of the TiNb alloy [12]. Furthermore, the $\mathrm{Nb}$ addition can enhances the $\beta$ phase stabilization during solution before the cold working, and can also affects the hardness during aging.

The main objective of the present study is to investigate the effect of cold working and the solution heat treatment on microstructure and microhardness of the Ti35 Nb2.5Sn alloy.

\section{Experimental procedure}

Ti35 $\mathrm{Nb} 2.5 \mathrm{Sn}$ alloys were obtained from commercial $\mathrm{Ti}, \mathrm{Nb}$ and $\mathrm{Sn}$ pure bars. The $280 \mathrm{~g}$ ingots were arc melted by means of a non-consumable tungsten electrode used

${ }^{\prime}$ Instituto Federal de Educação, Ciência e Tecnologia da Bahia - IFBA, Campus Santo Amaro, Santo Amaro, Brasil.

2Programa de Pós-graduação em Ciência e Engenharia de Materiais - P2CEM, Universidade Federal de Sergipe - UFS, São Cristóvão, SE, Brasil.

*Corresponding author: gustavo.lima@ifal.edu.br 
under controlled argon atmosphere in a water-cooled copper crucible (Analog Instrumentation and Control, model AN9270). They were homogenized in argon atmosphere at $1000{ }^{\circ} \mathrm{C}$ for $4 \mathrm{~h}$ and left to cool inside the oven (model FL-1300 Maitec) after reaching the homogenization time. The ingots were then hot rolled at $850^{\circ} \mathrm{C}$, followed by water quenching, in order to obtain plates with $40 \%$ true strain. Cylindrical samples with a diameter of $3 \mathrm{~mm}$ and a height of $10 \mathrm{~mm}$ were machined for the cold working process. The height of the samples was in the rolling direction. The cold working reduction of $40 \%$ (final height of $6.7 \mathrm{~mm}$ ), $70 \%$ (final height of $5.0 \mathrm{~mm}$ ), $80 \%$ (final height of $4.5 \mathrm{~mm}$ ) and $90 \%$ (final height of $4.1 \mathrm{~mm}$ ) were applied by compression of 3 samples for each strain level. The cold working was performed by universal machine (Instron $3385 \mathrm{H}, 250 \mathrm{kN}$ ). The compression in each sample was performed at speed of $1 \mathrm{~mm} / \mathrm{min}$. For this study, the symbols W40, W70, W80 and W90 were assigned to each cold work reduction level applied, respectively. After the cold working, each sample was cut off in its plane of symmetry. The specimens were then divided into two groups. In half of them, solution and quenching treatment was performed, providing four new groups: WQ40, WQ70, WQ80 and WQ90 (WQ corresponds to the cold working, solution and quenching condition).

The solution heat treatment was performed at $900{ }^{\circ} \mathrm{C}$ for $15 \min$ (INTI FL-1300) and it was followed by ice-quenching at $0{ }^{\circ} \mathrm{C}$. This treatment aimed to promotes the largest number of nucleation points for new grains from the $\beta$ phase field. The solutions treatments were carried out in air without atmosphere control.

The metallographic samples were embedded in metallographic resin and sanded up to $1500 \mathrm{Mesh}$, polished in alumina solution (particle size: $0.3 \mu \mathrm{m}$ ). The chemical etching was achieved by Kroll's solution $\left(12 \mathrm{ml} \mathrm{HNO}_{3}\right.$, $6 \mathrm{ml} \mathrm{HF}$ and $82 \mathrm{ml} \mathrm{H}_{2} \mathrm{O}$ ). The microstructural analysis was performed by optical microscope (Carl ZEISS Axio SCOPE A1). The X-ray diffraction analysis (XRD-6000 Shimadzu) was performed to identify the presence of different phases, at each condition described in the methodology. The parameters applied to the analysis were $\mathrm{Cu}$ Ka radiation $(\mathrm{k}=1.54 \AA)$, $40 \mathrm{kV}, 30 \mathrm{~mA}, 1.2^{\circ} / \mathrm{min}$ scanning at $30^{\circ} \leq 2 \theta \leq 90^{\circ}$. The phases were identified according to data from the JCPDS (Joint Committee of Powder Diffraction Standards).

Vickers microhardness tests [13], with load of 19,62 N applied during 15 seconds, were performed (Future Tech FM-800) by five indentations on each metallographic sample. The differences between microhardness tests were compared by t-test, using One Way ANOVA at significance level $\mathrm{p} \leq 0.05$.

\section{Results and discussion}

\subsection{Microstructural features}

The metallography of the Ti35 $\mathrm{Nb} 2.5 \mathrm{Sn}$ alloy at the conditions presented in the methodology can be seen in Figure 1. It can be noted the coarse $\beta$ grains without considerable slip bands in the W40 alloy, which denotes that Ti35Nb2.5Sn alloy undergoes good strain capacity, as the $40 \%$ strain did not interfere in the form of the primary $\beta$ grains. It can be confirmed by other study [14].

Figure 1 shows some slip bands at the primary $\beta$ grains of the W40 alloy, and also fine needles related to the strain induced martensite $\alpha$ " phase. For the solutioned and quenched WQ40 condition, new smaller $\beta$ grains can be seen elongated in the rolling direction. In addition, the grain size distribution is still heterogeneous, which may occur due to abnormal grain growth or secondary recrystallization process. Smaller $\beta$ grains can be nucleated from $\alpha$ " phase particles induced by strain and/or from slip bands present in the $\beta$ matrix of the strained alloys [9], since the formation of the new $\beta$ grains occurs at preferential sites located in the slip bands or dislocation clusters, or even from sub-grains of the metastable phases contained within the primary $\beta$ grains. For the W80 condition, $\alpha$ " needles can be seen within primary $\beta$ grains, between slip bands, and in sites closer to the grain boundaries. New $\beta$ grains were formed after solution and quenching of the WQ80 condition. The microstructure is similar in both conditions WQ70 and WQ80.

Figure 1 also denotes the microstructure of the W90 and WQ90 conditions. The higher work hardening promoted the formation of several slip bands in the microstructure of the W90 condition. Needles of the $\alpha$ " crossing the grains between the slip bands. Figure 1 also shows the coarse $\beta$ primary grain boundaries of the cold worked alloys. Microstructure formed mainly by $\beta$ grains is denoted in the metallography of the WQ90 condition, whose heat treatment promoted the reverse transformation of the $\alpha$ " phase to the $\beta$ phase and also promoted the nucleation of the $\beta$ phase from slip bands. Several $\beta$ grains formed at the same time and being abruptly cooled, maintained their structure and promoted homogeneously dispersed grains.

\subsection{XRD analysis}

The results described in the previous section can be confirmed by XRD analysis. For the W40 condition, Figure 2 denotes the $\beta$ and $\alpha$ " phases, which confirms the presence of these phases previously established in the metallography (Figure 1). The XRD analyzes presented the peaks of the $\alpha$ " phase, which can be related to the cold working [9]. Peak of the $\omega$ phase is observed, which is generated by the collapse of the $\beta$ planes or by the effect of twins. Other studies have reported that the $\omega$ phase can be induced by strain $[15,16]$.

The $\alpha$ " phase occurs for the WQ80 condition, although it was not found in WQ70. The solution heat treatment encouraged the nucleation of new grains from this phase and they were held after ice-quenching. Furthermore, the $\alpha$ " phase could be not detected in the WQ70 condition because microstructural heterogeneities and the lower intensity of the phase. Other features of the XRD analysis denoted in Figure 2 are the widening and offsetting of the diffraction 

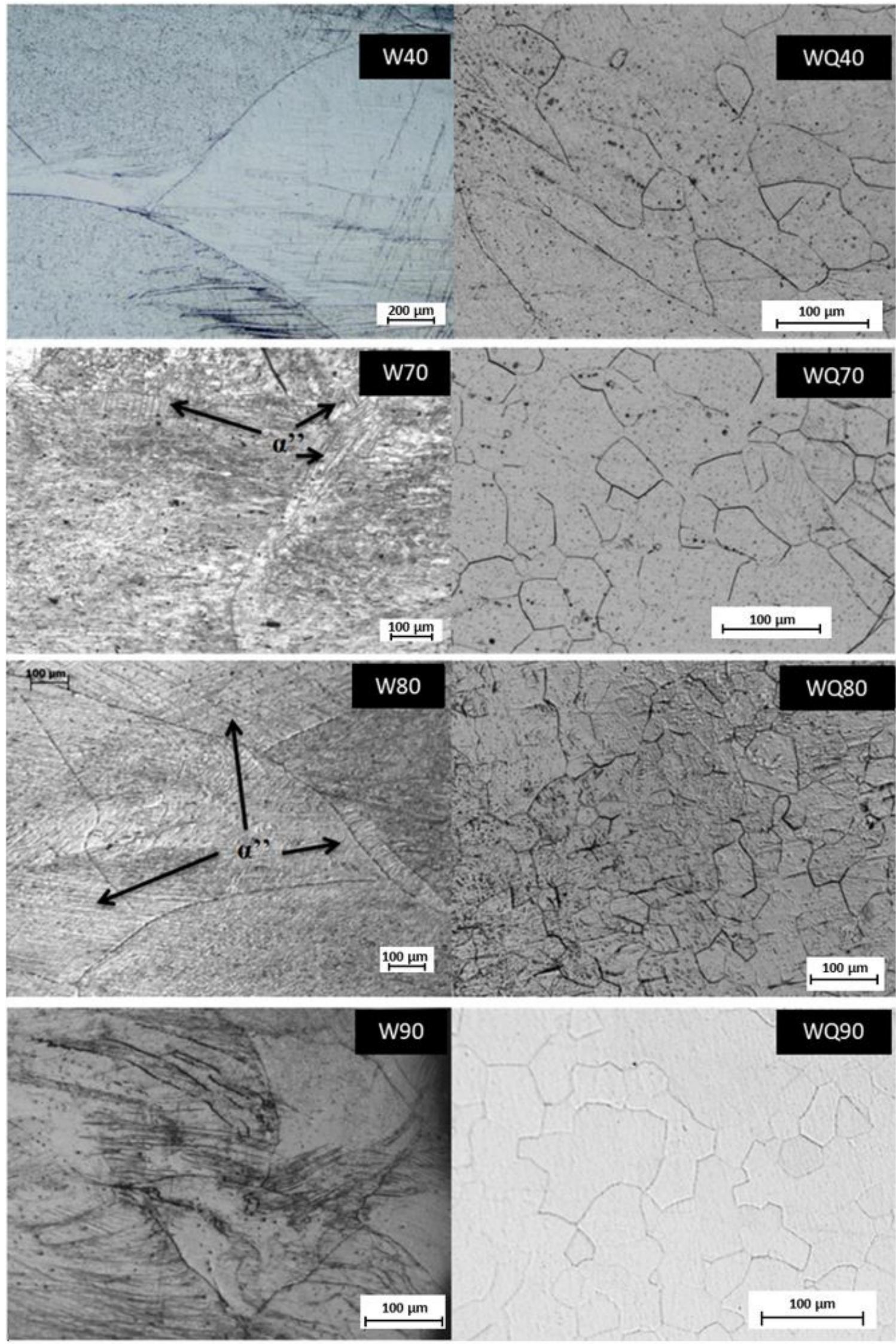

Figure 1. Microstructure of Ti35Nb2.5Sn alloy subjected to compressive of $40 \%, 70 \%, 80 \%$ and $90 \%$ before (W40, W70, W80 e W90) and after the solution treatment at $900{ }^{\circ} \mathrm{C}$ for $15 \mathrm{~min}$ followed by ice-quenching at $0{ }^{\circ} \mathrm{C}$ (WQ40, WQ70, WQ80 and WQ90). 

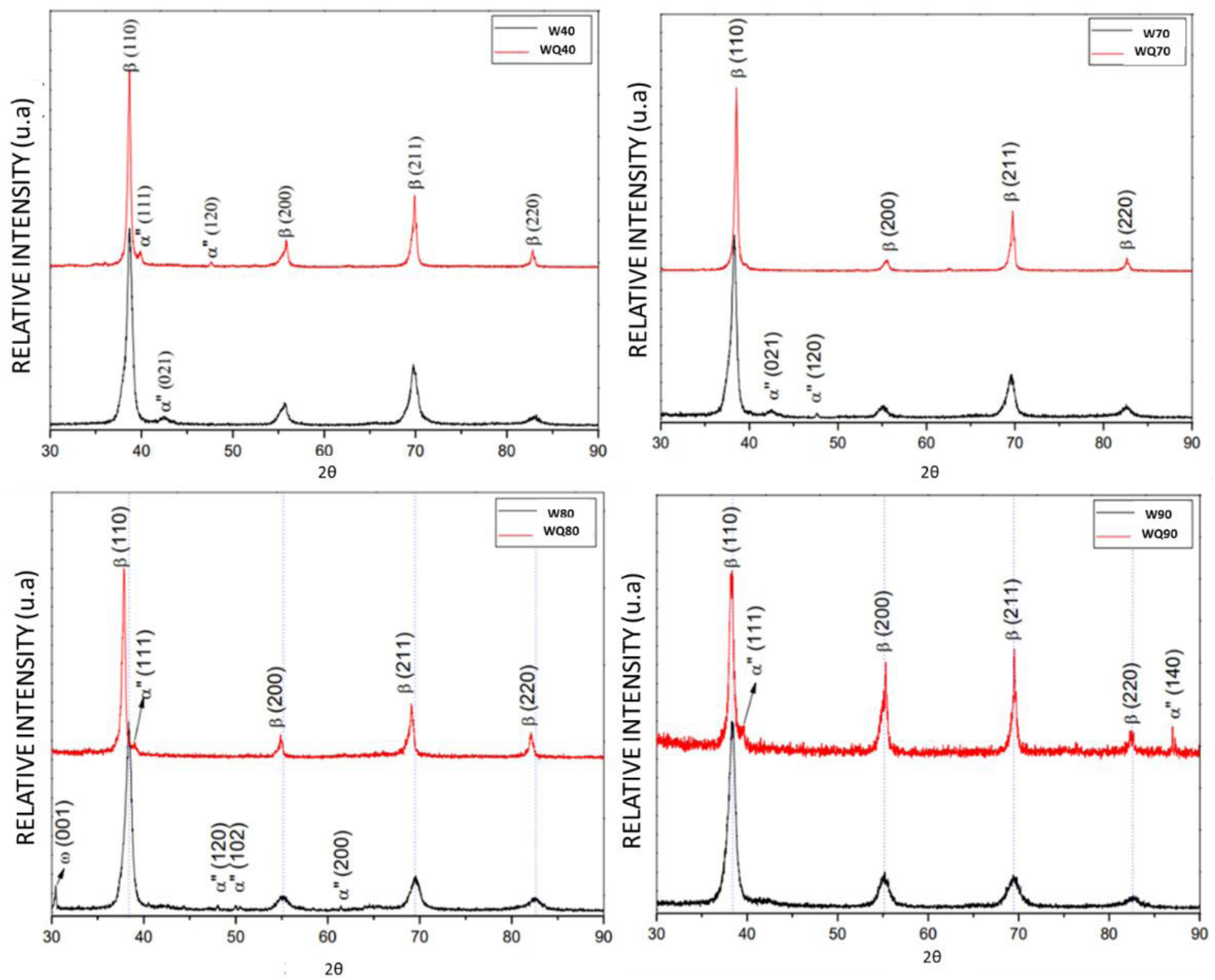

Figure 2. X-ray diffractogram of the Ti35Nb2.5Sn alloy with $40 \%, 70 \%, 80 \%$ e $90 \%$ strain before (W40, W70, W80 e W90) and after the solution treatment at $900{ }^{\circ} \mathrm{C}$ for 15 min followed by ice-quenching at $0{ }^{\circ} \mathrm{C}$ (WQ40, WQ70, WQ80 and WQ90).

peaks of condition W80, when compared to the WQ80. These phenomena can be associated with the strain that causes distortion of the lattice parameter and disorder in the atomic structure, promoting residual stresses, which interfere with the path taken by the X-ray beam and thus resulting in displacement of the diffraction peaks $[17,18]$. The XRD analysis confirms the presence of peaks of the $\alpha$ " phase and also of the $\beta$ phase, as shown in Figure 1.

XRD analysis also denotes the needles recognized in metallography as being of the $\alpha$ " phase, as in the WQ90 condition. It can be seen the $\alpha$ " phase was not detected in XRD analysis of the W90. As stated earlier, it may be related to microstructural heterogeneities, since the X-ray beam could be focused on a site of lower amount of $\alpha$ " phase or that the volumetric fraction of this phase is below the percentage detectable by XRD. Despite the limitations of the XRD analysis, the technique showed that the martensitic phase $\alpha$ " occurs in greater intensity in the deformed alloys.

\subsection{Microhardness analysis}

Microhardness before cold work was determined in a previous work of our group [5]. The mean microhardness was $205 \mathrm{HV}$. The microhardness of the alloy does not vary significantly between $40 \%$ and $70 \%$ strain (Figure 3 ). However, the hardness decreases after the heat treatment of solution and quenching, which must be related to the contribution of recrystallization and/or the increase in $\beta$ phase amount in the alloy after solution and quenching. Therefore, the heat treatment encouraged the $\beta$ stabilization for $40 \%$ and $70 \%$ strain. Consequently, the volume fraction of the $\alpha$ " phase in the respective untreated alloys was reduced, keeping the microhardness in a lower level.

The microhardness increased for W80, W90, WQ80 and WQ90. It is noticed that the microhardness increased in greater proportion for the solubilized and quenched alloys (WQ), when compared to the samples submitted to cold working (W). Microhardness differed significantly between the 


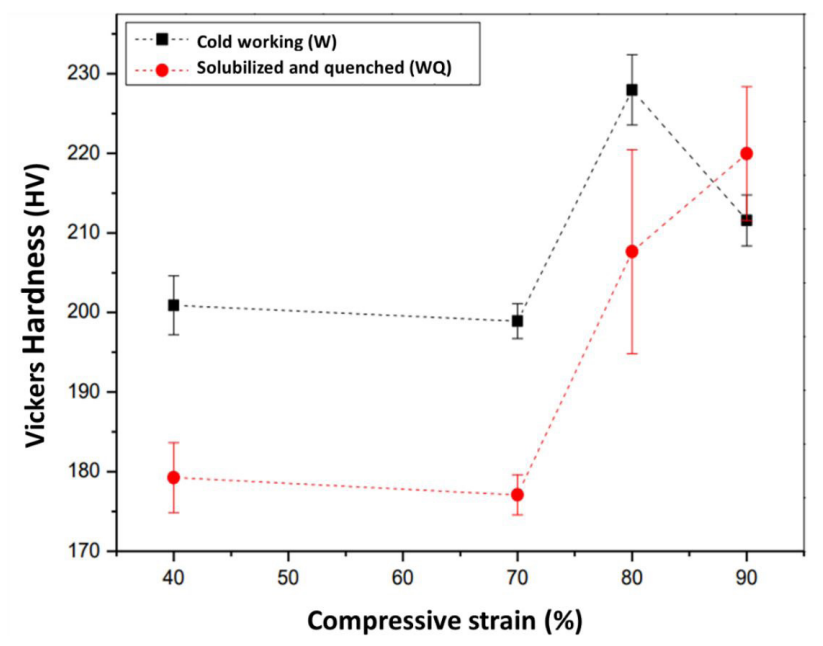

Figure 3. Vickers microhardness versus compression strain. The error bars refer to the 0.95 confidence interval.

two groups W and WQ. Furthermore, there was stabilization of the microhardness up to $70 \%$ strain. The microhardness increases significantly for $80 \%$ strain, holding significant difference between the two groups W and WQ. Although the microhardness of the W90 group decreased, there is no significant difference between the two groups. This reduction may be related to microstructural heterogeneities.

It is supposed that the Vickers microhardness increased between W80 and W90 because of the amount of strain induced $\alpha$ ", the amount of the $\omega$ phase - when it is present, and also by the dislocation density. The microhardness increase after the ice quenching could be due to the formation of metastable phases on the $\beta$ matrix. The $\alpha$ " and $\omega$ phases were detected by XRD analysis for some samples, although it was not possible to quantify the phases due to the low volume fraction. The grain size must also have influenced microhardness. The microstructural analysis previously described denotes that the grains of the heat-treated alloys are being refined as the cold working increases. Furthermore, higher cold working such as the 80 and $90 \%$ provided in the present study promotes the grain size homogeneity, without the presence of abnormal grain growth as that found for $40 \%$ strain. Therefore, in addition to the phase transformation effects noted earlier, the increase in microhardness can also be attributed to microstructural refinement.

\section{Conclusions}

The main purpose of this study was to investigate the relation between cold working, solution and quenching heat treatment, microstructure and microhardness of the Ti35 Nb2.5Sn alloy after using different levels of cold reduction. The following conclusions can be found in this study:

- The XRD analysis showed that the $\alpha$ " phase amount is higher in the alloys submitted to cold work and it is reduced or suppressed in the alloys after solution and quenching;

- The microhardness did not increase in the alloy deformed up to $70 \%$ strain;

- When the alloy is cold-worked above $70 \%$, the microhardness increases significantly as effect of microstructural disorder level denoted by slip bands and the higher amount of $\alpha$ " phase formed by strain;

- The microhardness increase is held after quenching as effect of $\beta$ grain refinement encouraged by the microstructural disorder level after cold working.

\section{Acknowledgements}

The authors would like to thank the following agencies (CNPq, Fapitec and Capes).

\section{References}

1 Guo S, Meng QK, Cheng XN, Zhao XQ. Deformation behavior of metastable $\beta$-type Ti-25Nb-2Mo-4Sn alloy for biomedical applications. Journal of the Mechanical Behavior of Biomedical Materials. 2014;38:26-32. http://dx.doi. org/10.1016/j.jmbbm.2014.06.006.

2 Hou YP, Guo S, Qiao XL, Tian T, Meng KQ, Cheng XN, et al. Origin of ultralow young's modulus in a metastable $\beta$-type Ti-33Nb-4Sn alloy. Journal of the Mechanical Behavior of Biomedical Materials. 2016;59:220-225. http:// dx.doi.org/10.1016/j.jmbbm.2015.12.037.

3 Nazari KA, Nouri A, Hilditch T. Mechanical properties and microstructure of powder metallurgy Ti-xNb-yMo alloys for implant materials. Materials \& Design. 2015;88:1164-1174. http://dx.doi.org/10.1016/j.matdes.2015.09.106.

4 Zhentao Y, Lian Z. Influence of martensitic transformation on mechanical compatibility of biomedical $\beta$ type titanium alloy TLM. Materials Science and Engineering A. 2006;438-440:391-394. http://dx.doi.org/10.1016/j. msea.2005.12.079.

5 Griza S, Souza Sá DHG, Batista WW, De Blas JCG, Pereira LC. Microstructure and mechanical properties of hot rolled TiNbSn alloys. Materials \& Design. 2014;56:200-208. http://dx.doi.org/10.1016/j.matdes.2013.10.067. 
6 Azevedo TF, Andrade CEC, Santos SV, Silva AS, Griza S. Fatigue and corrosion-fatigue strength of hot rolled Ti35Nb2.5Sn alloy. Materials \& Design. 2015;85:607-612. http://dx.doi.org/10.1016/j.matdes.2015.07.045.

7 Guo Q, Zhan Y, Mo H, Zhang G. Aging response of the Ti-Nb system biomaterials with $\beta$-stabilizing elements. Materials \& Design. 2010;31(10):4842-4846. http://dx.doi.org/10.1016/j.matdes.2010.05.047.

8 Hanada S, Masahashi N, Jung TK, Yamada N, Yamako G, Itoi E. Fabrication of a high-performance hip prosthetic stem using $\beta$ Ti-33.6Nb 4Sn. Journal of the Mechanical Behavior of Biomedical Materials. 2014;30:140-149. http:// dx.doi.org/10.1016/j.jmbbm.2013.11.002.

9 Matsumoto H, Watanabe S, Hanada S. Microstructures and mechanical properties of metastable TiNbSn alloys cold rolled and heat treated. Journal of Alloys and Compounds. 2007;439(1-2):146-155. http://dx.doi.org/10.1016/j. jallcom.2006.08.267.

10 Hanada S, Masahashi N, Jung TK, Miyake M, Sato YS, Kokawa H. Effect of swaging on Young's modulus of $\beta$ Ti-33.6Nb-4Sn alloy. Journal of the Mechanical Behavior of Biomedical Materials. 2014;32:310-320. http://dx.doi. org/10.1016/j.jmbbm.2013.10.027.

11 Azevedo TF, Lima TN, Blas JG, Pereira LC. The mechanical behavior of TiNbSn alloys according to alloying contents, cold rolling and aging. Journal of the Mechanical Behavior of Biomedical Materials. 2017;75:33-40. http:// dx.doi.org/10.1016/j.jmbbm.2017.07.002.

12 Ozaki T, Matsumoto H, Watanabe S, Hanada S. Beta Ti alloys with low Young's Modulus. Materials Transactions. 2004;45(8):2776-2779. http://dx.doi.org/10.2320/matertrans.45.2776.

13 ASTM International. ASTM 384-11: standard test method for knoop and vickers hardness of materials. West Conshohocken: ASTM; 2011.

14 Sá DHG. Caracterização metalúrgica e mecânica de ligas de Ti-Nb-Sn laminadas a quente para uso biomédico [thesis]. São Cristovão: P2CEM, Universidade Federal de Sergipe; 2013.

15 Hanada S, Yoshio T, Izumi O. Effect of plastic deformation modes on tensile properties of beta titanium alloys. Transactions of the Japan Institute of Metals. 1986;27(7):496-503. http://dx.doi.org/10.2320/matertrans 1960.27.496.

16 Ishiyama S, Hanada S, Izumi O. Effect of $\mathrm{Zr}$, Sn and $\mathrm{Al}$ additions of deformation mode and beta phase-stability of metastable beta Ti alloy. ISIJ International. 1991;31(8):807-813. http://dx.doi.org/10.2355/isijinternational.31.807.

17 Ungár T. Microstructural parameters from X-ray diffraction peak broadening. Scripta Materialia. 2004;51(8):777781. http://dx.doi.org/10.1016/j.scriptamat.2004.05.007.

18 Ceglias RB, Alves JM, Botelho RA, Baeta ES Jr, Santos IC, Moraes NRDC, et al. Residual stress evaluation by X-ray diffraction and hole-drilling in an API 5L X70 steel pipe bent by hot induction. Materials Research. 2016;19(5):1176-1179. http://dx.doi.org/10.1590/1980-5373-MR-2016-0012.

Received: 14 Aug. 2020

Accepted: 11 Nov. 2020 